\title{
RESEARCH
}

Open Access

\section{Development of Australian physical activity and screen time guidelines for outside school hours care: an international Delphi study}

Rosa Virgara ${ }^{1 *}$ D, Anna Phillips', Lucy Lewis ${ }^{2}$, Mandy Richardson ${ }^{3}$ and Carol Maher ${ }^{1}$

\begin{abstract}
Background: Children's activity patterns in the periods before and after school make a key contribution to achieving 24-h movement guidelines. There are currently no national-level guidelines informing physical activity and screen time practices in Outside School Hours Care (OSHC) programs anywhere in the world. This study aimed to work with industry, government and academic stakeholders to develop draft physical activity and screen time guidelines for use in Australian OSHC.
\end{abstract}

Methods: A 4-round online Delphi survey was conducted from May 2019 to January 2020. The Delphi participants included national and international experts and stakeholders from academia, education, government, health and the OSHC sectors. Round 1 consisted of open-ended questions exploring physical activity, screen time and sedentary behaviour in various periods of OSHC (before school, after school and vacation care). In rounds 2 and 3, participants rated the importance of items generated from the first round for inclusion in national guidelines using a Likert scale (1-9). Consensus was defined a priori as $\geq 80 \%$ of respondents rating an item as "critically important" (score 7-9). Between rounds 3 and 4, the guideline development panel used the consensus items, systematic review evidence, and followed the GRADE process, to draft the guidelines. In round 4, participants were invited to provide feedback on the draft guidelines and comment on barriers and enablers to implementation.

Results: Sixty-seven stakeholders agreed to participate, with response rates $61,81,54$ and $72 \%$ for the four rounds respectively. Of the 123 items generated across the three rounds, 48 statements achieved consensus agreement as critically important for inclusion in the guidelines. These included offering a variety of physical activities (free play, playground and equipment) and restriction of screen time. The final round provided feedback on the draft guidelines. The wording of the guidelines was found to be appropriate and preliminary enablers and barriers to implementation were identified.

Conclusions: This world-first expert and stakeholder consultation has underpinned the development of the draft Australian guidelines for physical activity and screen time in OSHC. Ongoing work is needed to further refine the guidelines, determine current rates of compliance with the guidelines and implement the guidelines into practice.

Keywords: Physical activity, Screen time, Delphi, Outside school hours care, Guidelines, GRADE

\footnotetext{
* Correspondence: Rosa.virgara@mymail.unisa.edu.au

${ }^{1}$ Allied Health and Human Performance, University of South Australia, c/o

GPO Box 2471, SA 5001 Adelaide, Australia

Full list of author information is available at the end of the article
}

C C The Author(s). 2020 Open Access This article is licensed under a Creative Commons Attribution 4.0 International License, which permits use, sharing, adaptation, distribution and reproduction in any medium or format, as long as you give appropriate credit to the original author(s) and the source, provide a link to the Creative Commons licence, and indicate if changes were made. The images or other third party material in this article are included in the article's Creative Commons licence, unless indicated otherwise in a credit line to the material. If material is not included in the article's Creative Commons licence and your intended use is not permitted by statutory regulation or exceeds the permitted use, you will need to obtain permission directly from the copyright holder. To view a copy of this licence, visit http://creativecommons.org/licenses/by/4.0/ The Creative Commons Public Domain Dedication waiver (http://creativecommons.org/publicdomain/zero/1.0/) applies to the data made available in this article, unless otherwise stated in a credit line to the data. 


\section{Introduction}

Widely adopted 24-h movement guidelines recommend that children aged 5 to 18 years achieve $60 \mathrm{~min}$ of moderate- to- vigorous physical activity (MVPA) a day, limit recreational screen time to no more than $2 \mathrm{~h}$ and achieve at least 9-11 h' sleep for children aged 5-13 years or 8$10 \mathrm{~h}$ for children aged 14-17 years [1-4]. Achieving this balance of physical activity (PA) and sedentary behaviours is linked to a multitude of improved health and wellbeing outcomes for children $[5,6]$.

As few as 1 in 4 children achieve the recommended amount of MVPA [7] and 1 in 3 meet screen time guidelines [8]. The hours out of school hours are a key time of the day for the accumulation of PA and sedentary behaviours $[9,10]$. As many as $18 \%$ of children in the US [11] and approximately $10 \%$ of Australian children [12] attend outside school hours care (OSHC). This rate is even higher in some countries, such as Norway, where $81 \%$ of 6 -year-olds attend OSHC [13]. A study of Australian children (mean age 8.1 years) found that the after-school period $(3-6 \mathrm{pm})$ accounted for $30 \%$ of children's daily MVPA, 25\% of their light PA and $80 \%$ of their recreational screen time [10]. Therefore it appears that the OSHC setting holds considerable promise for positively impacting the PA and screen time behaviours of vast numbers of children.

In recent years, some interventions in OSHC have been framed around guidelines for PA in this setting [14-16]. A recent scoping review identified that all guidelines for PA and/or screen time in the OSHC setting have been produced for states or provinces or other regional areas of the US and Canada [17]. None have been national in scope, and none have followed rigorous methodologies during development or publication (i.e. they have not followed rigorous established guideline development methodologies, such as Grading of Recommendations, Assessment, Development and Evaluation (GRADE) [18] or Guideline International Network (G-IN) [19] methodologies, and all guidelines to date have been published in the grey-literature). In addition, the guidelines to date have varied in the behaviours of interest, (MVPA vs moderate PA vs vigorous PA), whether they cover screen time in addition to PA or not, and whether they cover both before and after school periods. Furthermore, the amount of PA recommendations vary in terms of duration and intensity. The variation in these recommendations, and methodological concerns, make the adoption of these guidelines into other world regions questionable; unlike the 24-h movement guidelines which have consistent messaging and are widely adopted across Australia [1], Canada [2], Croatia [3], Finland [20], New Zealand [4] and South Africa [21].

This study aimed to address these gaps, by extensively consulting stakeholders and following rigorous processes to develop draft guidelines targeting PA and screen time for use in Australian OSHC.

\section{Method \\ Research design}

This was a two-part study. Firstly, an international Delphi survey was conducted to obtain consensus opinion from a range of experts and stakeholders regarding children's PA and screen time behaviours in OSHC to inform the draft guidelines. A Delphi survey was used as it is a well-established methodology using prospective surveys [22]. It allows for stakeholders to provide insight into important elements for inclusion in the guidelines [22]. Unlike other well established guideline development tools, it was anticipated the Delphi survey would identify issues not apparent in the scientific literature and allow stakeholder engagement and thus potentially result in improved uptake and implementation of the final guidelines [22]. Secondly, the GRADE approach was applied to draft the guidelines. GRADE is used for both clinical guideline development and public health guidelines and is considered the gold standard in guideline development, endorsed and used by the World Health Organisation and NHMRC Australia [23]. A guideline development panel, consisting of the authorship team and four international experts in the field of PA, screen time and implementation research; followed the GRADE approach to draft the guidelines.

The research complies with the recommendations from the Conducting and Reporting of Delphi Studies (CREDES) [24]. Ethical approval was provided by the University of South Australia Human Research Ethics Committee (protocol no. 201786).

\section{Participant eligibility and panel recruitment}

Participants from a range of stakeholder groups involved in the OSHC setting and/or children's PA and screen time were sought for this Delphi survey. These included national and international researchers (identified as senior authors or renowned researchers in the field of PA and/or screen time), OSHC educators (identified as a Director of an OSHC or senior role in the service), school educators (e.g. school Principals), health professionals (e.g. senior Paediatrician's within a tertiary health service), government personnel (staff working in a department directly linked to PA) and parents of children attending OSHC services, with an emphasis on geographical diversity so that government and OSHC personnel from all Australian states were included. Full inclusion criteria are provided in Supplementary File 1. Hsu and Sanford [25] recommend that "... if various reference groups are involved in a Delphi study, more subjects are anticipated to be needed" p.3, rather than the usual 15-20 that are used in Delphi surveys [25]. Thus, 
to ensure representativeness of all stakeholder groups, at least 50 participants were required.

Potential participants were contacted by email outlining the study information (aims and rationale, the time commitment required and a link to the participant information sheet). If the participant opened the first round survey link, they were considered to have shown interest in the study. Completing the survey was considered consent to participate in the study. Participants were encouraged to complete all rounds of the Delphi to minimise attrition and reminded they could withdraw at any stage or continue with subsequent rounds if they had not completed the preceding round.

\section{Delphi surveys}

A maximum of four rounds were planned. Surveys were conducted using LimeSurvey $^{\mathrm{Tm}}$ software (www.limesurvey.org) [26], with each survey round piloted with people who were not participants in the Delphi proper. Delphi proper participants had 21 days to complete each survey round, with reminder emails sent at days 14, 20 and 21 .

\section{Pilot testing}

Round 1 was piloted by four people ( 2 academics, 1 government personnel and 1 school educator) to ensure appropriateness of the questionnaire items, wording, functionality, and identify any issues or gaps. No changes in wording were made to the first round questionnaire.

\section{Delphi proper - round 1}

Round 1 commenced in June 2019. To minimise the potential for personal bias from the research team guiding results [27], the first round focussed on 11 open-ended questions. Participants were provided with an explanation of the survey, and a request for demographic information (including confirmation of email address, location, highest level of education attained, stakeholder group, job title, employer organization, duration of employment, duration of use of OSHC and aspect of OSHC involved in). In addition, they were provided with definitions of OSHC, PA, screen time, before school care, after school care and vacation care. Questions exploring the perceived importance of children's PA, recreational screen time and sedentary behaviour, across the three OSHC time periods (before school, after school and vacation care) were asked. Round 1 responses were categorised into themes by the lead author (RV) and cross-checked by the research team (AP, LL, CM and MR). A summary of the entire Delphi process is provided in Fig. 1.

\section{Round 2}

Round 2 was developed based on themes from the Round 1 analysis. It comprised of 109 items, relating to PA (type of play e.g. free play/indoor/outdoor; activity intensity e.g. light, moderate, vigorous; session focus e.g. prepare for school day/relax; 24-h movement guidelines), screen time (rules around usage; behaviour management; consistency with 24-h movement guidelines; children and families' expectations) and sedentary behaviour (type of activities offered e.g. cognitive/social/developmental; 24-h movement guidelines), examined across the three OSHC periods (before school, after school and vacation care). Participants received feedback from the first round consisting of demographic data and tables summarising response rate, key themes and frequency. Participants were invited to rate the importance of each item on a 9-point Likert scale, with 1-3 considered not important, 4-6 important but not critical, and 7-9 critically important. This scoring is consistent with the 9point GRADE methodology [22]. Examples of items participants were asked to rate were "How important is it during a before school care session to encourage children to engage in outdoor active play" and "How important is it during an after school care session to provide tight limits for recreational screen time use?" Consensus was defined a priori as $\geq 80 \%$ participant agreement, meaning $\geq 80 \%$ of respondents had to rate the statement as being 'critically important' (i.e. $\geq 80 \%$ or more of scores were between 7 and 9) for inclusion in the draft guidelines. Participants were also invited to provide any further comments after rating the item in each of the categories.

\section{Round 3}

Round 3 was developed from Round 2 analysis and administered in September 2019. Participants were invited to re-rate items which had not achieved consensus in Round 2; and invited to rate new items that were generated from free-text responses in the previous round. Participants were provided with a reminder of definitions, along with individual and group scores from Round 2 embedded into the survey to reduce participant burden and assist with re-rating (Fig. 2).

\section{Guideline development process}

On completion of Round 3, and as part of the GRADE process, the Guideline Development Panel met and drafted the guidelines using the items that achieved consensus from rounds 2 and 3 of the Delphi survey. These consensus items were used with the results from the scoping review of PA and screen time guidelines in OSHC [17] and the results of the systematic review of interventions to increase PA in OSHC [28]. These draft recommendations consisted of two components. The first section contained a "snapshot" guide which provided a quick reference for OSHC personnel to identify what time targets they should aim for in each session of OSHC. The information obtained from the reviews was used to inform the time targets. The second section was 


\section{Methods}

\section{Round 1:}

Open ended items asking about PA, Screen Time and Sedentary Behaviours in various aspects of OSHC (before school care, after school care and vacation care)

\section{Response Rate}

$67 / 110$

$61 \%$

Round 1 comments analysed thematically into questions for Round 2

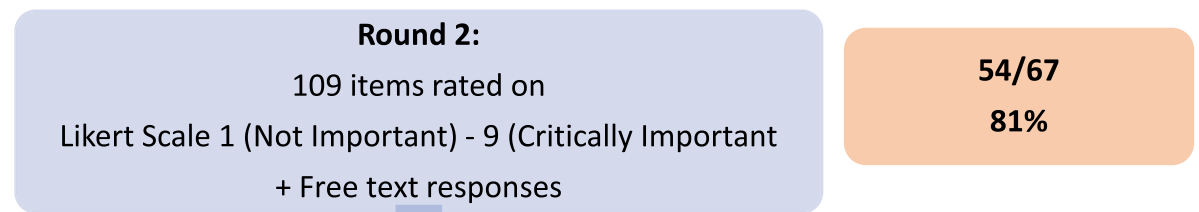

18 items achieved consensus; participants given

individual feedback imbedded into Round 3 survey

Round 3:

Re-rated 91 items from Round 2

+14 new items from Round 2 free text responses

+ Free text responses
$36 / 67$

$54 \%$

\section{Additional $\mathbf{3 0}$ items achieved consensus}

\section{Guideline Development Process}

Guideline development panel met, based on $\mathbf{4 8}$ consensus items + systematic review evidence
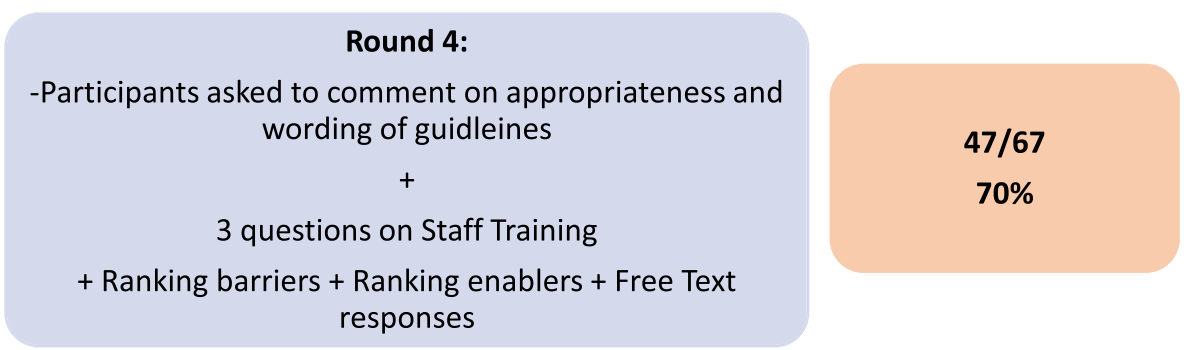
responses

Fig. 1 Delphi process in entirety

the elaboration document. This included a preamble providing the health effects associated with PA and screen time, a reference to the 24-h movement guidelines and how the OSHC environment can help children achieve the 24-h movement guidelines. The elaboration document made use of the items that met consensus in the Delphi to inform the content. These consensus items were incorporated into sections under the headings of PA recommendations, screen time recommendations and recommendations for educators.

\section{Round 4}

Round 4 commenced in December 2019 and closed in January 2020 and consisted of 13 questions. This 


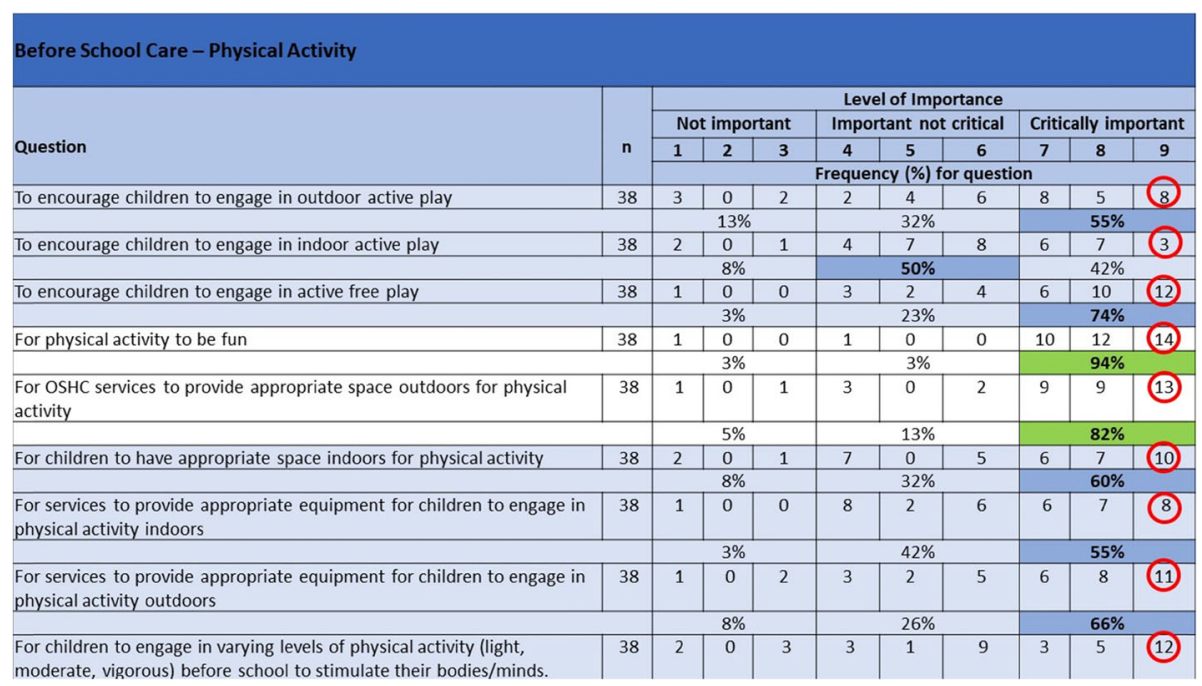

Fig. 2 Example participant result from round 2 embedded in round 3 Survey

included seven open-ended questions seeking comments on the wording of the draft guideline document, the durations recommended for PA and screen time and any additional comments. In addition, four multiple-choice questions asked about preferences for staff training on the guidelines (delivery mode, session length, educational materials), and two questions asking participants to rank the top three barriers and enablers to implementing such guidelines into practice. A final opportunity for any further comments was also provided.

\section{Data analysis and management}

Study uptake was calculated as the percentage of participants who opened the Round 1 Delphi survey from all potential participants contacted. Study retention rate was described as the percentage of participants completing the surveys and was calculated separately for each Delphi round. Participant characteristics were reported descriptively. For Likert scale items, all responses were used to calculate the mean, standard deviation (SD), median and mean absolute deviation from the median (MADM) (describes the variation in the median values) [29]. For consensus to be achieved, $\geq 80 \%$ of respondents must have rated the statement as being 'critically important' (i.e. Likert score between 7 and 9).

\section{Results}

\section{Delphi proper}

A total of 110 potential participants were identified and invited to be involved in the Delphi survey. Of those, $n=67$ provided informed consent (OSHC educators $(n=22)$, Parents $(n=14)$, Researchers/Academics $(n=$ 13), Government/NGO personnel $(n=8)$, Other $(n=5)$, unanswered $(n=5))$, leading to an uptake rate of $61 \%$.
Of those who didn't participate, $n=6$ declined participation and $n=37$ did not respond. The response rate for each round ranged from 54 to $81 \%$ (Fig. 1). All Australian states and territories were represented. The majority of participants were from Australia $87 \%(n=54)$ and $13 \%(n=8)$ of participants were international. Most participants had a Bachelor degree or higher $(71 \%, n=44)$, with a further $26 \%$ holding a graduate or trade certificate $(n=16)$.

\section{Round 1}

Participants were asked to provide comments about PA, screen time and sedentary behaviour across the three OSHC periods (before school care, after school care, and vacation care). Common themes that emerged were related to 24-h movement guidelines $(n=10)$, activities $(n=6)$, children and families $(n=6)$, rules $(n=3)$, staff $(n=3)$, type of play $(n=2)$, purpose of session $(n=2)$, and behaviour and training $(n=1)$ respectively. Themes that were common to all aspects across all OSHC time periods, were that recommendations should help children achieve the 24-h movement guidelines, and finally that staff, children and families should be involved in the implementation of such recommendations. Themes that were related to PA included type of activity (i.e. playbased PA, enjoyment of PA, and allowing for varying intensities of PA) and guidelines (24-h movement guidelines considered). The most common screen time theme regarded rules (i.e. limitations on quantity and content of screen time). Sedentary behaviour themes were also centred around 24-h movement guidelines and activity (i.e. they should allow for self-regulation, and play-based activities). Staff role modelling to encourage positive PA and screen time behaviours in the OSHC setting was 
prominent. Examples of participant statements are provided in Table 1:

\section{Round 2}

Round 2 of the Delphi survey consisted of 109 statements, consensus agreement was reached for 18 items, 13 relating to PA, two to screen time and four to "other" (scoring between 7 and 9 "critically important") to include in the guidelines (Table 2). Examples of the 13 PA items that reached immediate consensus as being critically important to include were "Physical activity to be fun" and "To provide opportunities for unstructured/free play to encourage physical activity" which achieved agreement of 94 and $97 \%$ respectively. An example of the screen time items that reached consensus was "That staff and older children model appropriate screen time use". No sedentary behaviour items achieved consensus in the first round.

Free text responses were provided by 18 participants. Themes were similar to Round 1, including activities, guidelines and rules. Free text responses for PA included providing appropriate provocations to encourage PA. Themes about rules were again prominent in responses to recreational screen time, and included free text responses about limiting screen time, particularly in after school care to counter the amount of screen time children have at home and during a school day. Some example comments are also provided in Table 1.

Themes in sedentary behaviour were around the benefits of sedentary activities (cognitive, social) and encouraging children to self-regulate.

\section{Round 3}

Round 3 consisted of 105 items for participants to rate (91 items that did not achieve consensus agreement and a further 14 new items developed from free-text responses provided by participants in Round 2). A further 30 items reached consensus as being "critically important" to include in the guidelines at the end of Round 3 (Table 3). Twelve items were relating to PA, six to screen time, ten to sedentary behaviour and a further two in the "other" category. Key PA items across all time periods of OSHC included that PA should be fun, incorporate free/unstructured play, indoor and outdoor play, opportunities for varying ages and abilities and for OSHC educators to consider the 24-h movement guidelines when scheduling PA at OSHC. Key screen time statements included limiting screen time, engagement with families and children about screen time practices in OSHC and ensuring vacation care does not exceed 24-h guideline limits. Sedentary behaviour items across OSHC time periods were strongly focussed around balancing between PA and quiet sedentary behaviour activities, with importance on encouraging children to self-regulate and move between activities. "Other" items that reach consensus focused on education and support provided to OSHC staff such as training and use of a policy or guideline document specifically for OSHC, incorporating elements of the Health Physical Education curriculum and integrating the 24-h movement guidelines when planning OSHC sessions.

\section{Guideline development process}

Following the conclusion of Round 3, the guideline development panel met on four occasions in November and December 2019, to draft the guidelines. Care was taken to balance data from the Delphi, including priorities, feasibility for the sector (based on feedback from industry advisor and comments in the Delphi) and including scientific content from the reviews $(17,28)$. The draft guideline document was created by the guideline development panel, and included a snapshot of the guidelines (Fig. 3) and the expanded guideline document (Supplementary File 2).

Table 1 Example Delphi participant open responses from Delphi rounds 1 and 2

\begin{tabular}{|c|c|c|}
\hline $\begin{array}{l}\text { Delphi } \\
\text { Round }\end{array}$ & Category & Delphi Participant Comment \\
\hline \multirow[t]{3}{*}{1} & PA - before school care & $\begin{array}{l}\text { "It's important for kids to wake up their mind and body before they start the day at school. Any form of } \\
\text { physical movement stimulates the body and mind, making the kids more receptive to learning. And it's also } \\
\text { fun." }\end{array}$ \\
\hline & $\begin{array}{l}\text { Screen time - after school } \\
\text { care }\end{array}$ & $\begin{array}{l}\text { "As little as possible. If screen time is used this should be active screen time (e.g. active video gaming or } \\
\text { geocaching)." }\end{array}$ \\
\hline & $\begin{array}{l}\text { Sedentary Behaviour - after } \\
\text { school care }\end{array}$ & $\begin{array}{l}\text { "Activities such as reading, board games construction/building activities should still be available for use. While } \\
\text { they may still be of a sedentary nature, they provide more opportunity for both social interaction and learning } \\
\text { compared to recreational screen time alone. However, still monitor the more sedentary activities and } \\
\text { encourage children to mix it up with outdoor active play." }\end{array}$ \\
\hline \multirow[t]{2}{*}{2} & $\begin{array}{l}\text { Screen time - after school } \\
\text { care }\end{array}$ & $\begin{array}{l}\text { "If screens are offered children will watch. Limit the offering and limit the watching. Don't want to demonise it, } \\
\text { the better approach is to offer more appealing alternatives that have a more active component." }\end{array}$ \\
\hline & Screen time - vacation care & $\begin{array}{l}\text { "As stated we do not use screens as much as possible and have seen a big change in behaviour and attitudes } \\
\text { from children". }\end{array}$ \\
\hline
\end{tabular}


Table 2 Items achieving consensus agreement from Delphi Round 2

\begin{tabular}{|c|c|c|c|c|}
\hline Statement & $\begin{array}{l}\text { Responses } \\
(n) \\
\text { All round } \\
2 n=54\end{array}$ & $\begin{array}{l}\% \text { agreement ( } \geq 7 \text { on } \\
9 \text { point Likert scale) }\end{array}$ & $\begin{array}{l}\text { Mean Likert } \\
\text { score (SD) }\end{array}$ & $\begin{array}{l}\text { Median } \\
\text { (MADM) }\end{array}$ \\
\hline \multicolumn{5}{|l|}{ Before School Care } \\
\hline \multicolumn{5}{|l|}{ Physical Activity } \\
\hline For physical activity to be fun & 43 & $95 \%$ & $7.9(1.5)$ & $8(0.9)$ \\
\hline For OSHC services to provide appropriate space outdoors for PA & 43 & $81 \%$ & $7.3(1.9)$ & $8(1.4)$ \\
\hline \multicolumn{5}{|l|}{ Screen Time } \\
\hline $\begin{array}{l}\text { That staff and older children in OSHC services role model appropriate screen } \\
\text { time use e.g. only access personal devices at beginning and end of sessions }\end{array}$ & 43 & $80 \%$ & $7.5(2.0)$ & $8(1.6)$ \\
\hline That recreational screen time should be limited & 43 & $81 \%$ & $7.2(2.2)$ & $7(1.6)$ \\
\hline \multicolumn{5}{|l|}{ After School Care } \\
\hline \multicolumn{5}{|l|}{ Physical Activity } \\
\hline To provide an opportunity for free play/unstructured physical activity & 39 & $95 \%$ & $8.2(1.1)$ & $9(0.9)$ \\
\hline To provide fun physical activity & 39 & $92 \%$ & $8.2(1.2)$ & $9(1.0)$ \\
\hline $\begin{array}{l}\text { To provide opportunity for outdoor play and outdoor equipment to encourage } \\
\text { physical activity }\end{array}$ & 39 & $92 \%$ & $8(1.1)$ & $8(0.9)$ \\
\hline To provide physical activity opportunities for children of different ages & 39 & $89 \%$ & $8.1(1.2)$ & $9(0.9)$ \\
\hline To provide physical activity opportunities for children of different abilities & 39 & $95 \%$ & $8.3(1.1)$ & $9(0.9)$ \\
\hline $\begin{array}{l}\text { To provide opportunities for varying intensities of physical activity (light, } \\
\text { moderate, moderate-vigorous, vigorous }\end{array}$ & 39 & $84 \%$ & $7.5(1.7)$ & $8(1.2)$ \\
\hline \multicolumn{5}{|l|}{ Screen Time } \\
\hline That physical activity is the preference to recreational screen time & 39 & $82 \%$ & $7.6(1.6)$ & $8(1.3)$ \\
\hline \multicolumn{5}{|l|}{ Vacation Care } \\
\hline \multicolumn{5}{|l|}{ Physical Activity } \\
\hline To provide a diverse range of physical activity throughout the day & 38 & $89 \%$ & $7.8(1.4)$ & $8(1.0)$ \\
\hline To provide opportunities for outdoor physical activity & 38 & $97 \%$ & $8.2(1.1)$ & $9(0.9)$ \\
\hline $\begin{array}{l}\text { To provide opportunities for unstructured/free play to encourage physical } \\
\text { activity }\end{array}$ & 38 & $97 \%$ & $8.3(1.0)$ & $9(0.9)$ \\
\hline To provide physical activity that is fun & 38 & $97 \%$ & $8.3(0.9)$ & $9(0.8)$ \\
\hline \multicolumn{5}{|l|}{ Other } \\
\hline $\begin{array}{l}\text { That OSHC educators are continually supported, upskilled and motivated to help } \\
\text { children achieve healthy activity behaviours }\end{array}$ & 36 & $86 \%$ & $7.5(1.2)$ & $7(1.0)$ \\
\hline $\begin{array}{l}\text { To provide a wide range of activities throughout the day in OSHC services with } \\
\text { recognition of the } 24 \mathrm{~h} \text { movement guidelines (i.e. balanced between physical } \\
\text { activity, sedentary behaviour and screen time }\end{array}$ & 36 & $83 \%$ & $7.6(1.4)$ & $8(1.1)$ \\
\hline $\begin{array}{l}\text { To use a guideline or policy to better guide physical activity, recreational screen } \\
\text { time and sedentary behaviours in OSHC }\end{array}$ & 36 & $81 \%$ & $7.6(1.3)$ & $8(1.1)$ \\
\hline
\end{tabular}

MADM Mean absolute deviation from median, SD Standard deviation

\section{Round 4}

Overall the draft Australian PA and screen time guidelines were considered by Delphi participants to provide appropriate durations of time recommended for the activities based on free-text responses $(n=25)$ agreement statements (e.g. "Agree", "Appropriate to me", "like the wording"). Of those who had concerns about the recommended time targets $(n=13)$, their comments included "Screen time in the afternoon should be no more than 30 minutes (versus 1 hour)" and "The physical activity times stipulated for both before and after school care could be challenging for children who are not there for the full session - some children may only attend after school care for 30 - 60 minutes so by the time they get there have a snack/afternoon tea etc they may not have time to do the suggested physical activity quota." Some participants did not provide any free text responses at all $(n=9)$.

The top three ranked barriers to implementing the guidelines were 1) educator beliefs, 2) workplace culture and 3) children's beliefs. The top 3 enablers to 
Table 3 Items achieving consensus agreement from Delphi Round 3

\begin{tabular}{|c|c|c|c|c|}
\hline Statement & $\begin{array}{l}\text { Responses (n) } \\
\text { Participated } \\
\text { Round } 3 n=36\end{array}$ & $\begin{array}{l}\% \\
\text { Agreement }\end{array}$ & $\begin{array}{l}\text { Mean } \\
\text { (SD) }\end{array}$ & $\begin{array}{l}\text { Median } \\
\text { (MADM) }\end{array}$ \\
\hline \multicolumn{5}{|l|}{ Before School Care } \\
\hline \multicolumn{5}{|l|}{ Physical Activity } \\
\hline To encourage children to engage in active free play & 34 & $80 \%$ & $\begin{array}{l}7.5 \\
(1.5)\end{array}$ & $8(1.2)$ \\
\hline To provide quality environments that enable free active play ${ }^{\#}$ & 34 & $85 \%$ & $\begin{array}{l}7.7 \\
(1.2)\end{array}$ & $8(1.0)$ \\
\hline To provide indoor or outdoor provocations to encourage active play ${ }^{\#}$ & 34 & $80 \%$ & $\begin{array}{l}7.3 \\
(1.4)\end{array}$ & $7(1.0)$ \\
\hline To encourage active play to provide social benefits ${ }^{\#}$ & 34 & $82 \%$ & $\begin{array}{l}7.5 \\
(1.4)\end{array}$ & $8(1.1)$ \\
\hline To provide activities which encourage children to be active ${ }^{\#}$ & 34 & $91 \%$ & $\begin{array}{l}7.9 \\
(1.2)\end{array}$ & $8(1.0)$ \\
\hline \multicolumn{5}{|l|}{ Screen Time } \\
\hline That active video gaming is allowed ${ }^{a}$ & 33 & $85 \%$ & $\begin{array}{l}2.2 \\
(1.5)\end{array}$ & $1(1.3)$ \\
\hline \multicolumn{5}{|l|}{ Sedentary Behaviour } \\
\hline To provide opportunities for free play & 31 & $90 \%$ & $\begin{array}{l}7.8 \\
(1.7)\end{array}$ & $8(1.1)$ \\
\hline To provide children the option to choose their activities/self-regulate & 31 & $81 \%$ & $\begin{array}{l}7.2 \\
(1.8)\end{array}$ & $7(1.3)$ \\
\hline \multicolumn{5}{|l|}{ After School Care } \\
\hline \multicolumn{5}{|l|}{ Physical Activity } \\
\hline For staff to have ongoing training support on ways to embed physical activity into policy & 30 & $87 \%$ & $\begin{array}{l}7.7 \\
(1.4)\end{array}$ & $8(1.2)$ \\
\hline For staff to have ongoing training about the benefits of physical activity & 30 & $87 \%$ & $\begin{array}{l}7.8 \\
(1.2)\end{array}$ & $8(1.0)$ \\
\hline \multicolumn{5}{|l|}{ Screen Time } \\
\hline $\begin{array}{l}\text { That there is engagement between staff and children and their families about the effects of } \\
\text { screen time }\end{array}$ & 30 & $80 \%$ & $\begin{array}{l}7.1 \\
(2.1)\end{array}$ & $7(1.4)$ \\
\hline $\begin{array}{l}\text { That the screen time recommendations in the } 24 \mathrm{~h} \text { movement guidelines are considered } \\
\text { when timetabling activities. }\end{array}$ & 30 & $80 \%$ & $\begin{array}{l}7.3 \\
(1.9)\end{array}$ & $7.5(1.4)$ \\
\hline \multicolumn{5}{|l|}{ Sedentary Behaviour } \\
\hline That sedentary activities are balanced with physical activity during after school care & 28 & $89 \%$ & $\begin{array}{l}7.6 \\
(1.1)\end{array}$ & $7(1.0)$ \\
\hline $\begin{array}{l}\text { That staff engage with children to help them move between activities (e.g. if spent a long } \\
\text { time in sedentary activities move to a physical activity, or if need to calm down participate } \\
\text { in a sedentary task) }\end{array}$ & 28 & $86 \%$ & $\begin{array}{l}7.4 \\
(1.3)\end{array}$ & $7(1.0)$ \\
\hline That children are encouraged to choose/self-regulate their sedentary activities & 28 & $82 \%$ & $\begin{array}{l}7.4 \\
(1.5)\end{array}$ & $7(1.2)$ \\
\hline To provide balanced periods between active and sedentary play & 28 & $82 \%$ & $\begin{array}{l}7.4 \\
(1.3)\end{array}$ & $7(1.1)$ \\
\hline \multicolumn{5}{|l|}{ Vacation Care } \\
\hline \multicolumn{5}{|l|}{ Physical Activity } \\
\hline To provide opportunities for indoor physical activity & 27 & $81 \%$ & $\begin{array}{l}7.3 \\
(1.6)\end{array}$ & $7(1.1)$ \\
\hline To balance the program between physical activities and sedentary activities & 27 & $89 \%$ & $\begin{array}{l}7.5 \\
(1.4)\end{array}$ & $7(1.1)$ \\
\hline To allow children the opportunity to choose their activity & 27 & $81 \%$ & $\begin{array}{l}7.6 \\
(1.7)\end{array}$ & $8(1.3)$ \\
\hline To consider the $24 \mathrm{~h}$ movement guidelines when scheduling the day & 27 & $85 \%$ & 7.4 & $8(1.3)$ \\
\hline
\end{tabular}


Table 3 Items achieving consensus agreement from Delphi Round 3 (Continued)

\begin{tabular}{|c|c|c|c|c|}
\hline Statement & $\begin{array}{l}\text { Responses (n) } \\
\text { Participated } \\
\text { Round } 3 n=36\end{array}$ & $\begin{array}{l}\text { \% } \\
\text { Agreement }\end{array}$ & $\begin{array}{l}\text { Mean } \\
\text { (SD) }\end{array}$ & $\begin{array}{l}\text { Median } \\
\text { (MADM) }\end{array}$ \\
\hline & & & $(1.7)$ & \\
\hline $\begin{array}{l}\text { To educate staff and children re: benefits of the } 24 \mathrm{~h} \text { movement guidelines and importance } \\
\text { of achieving them }\end{array}$ & 27 & $85 \%$ & $\begin{array}{l}7.4 \\
(1.8)\end{array}$ & $8(1.3)$ \\
\hline \multicolumn{5}{|l|}{ Screen Time } \\
\hline $\begin{array}{l}\text { To involve children and families in decision making around recreational screen time } \\
\text { practices }\end{array}$ & 27 & $81 \%$ & $\begin{array}{l}7.3 \\
(2.2)\end{array}$ & $8(1.6)$ \\
\hline $\begin{array}{l}\text { To provide education to children and families about the effects of excessive recreational } \\
\text { screen time }\end{array}$ & 27 & $89 \%$ & $\begin{array}{l}7.7 \\
(1.8)\end{array}$ & $8(1.2)$ \\
\hline $\begin{array}{l}\text { To ensure vacation care does not exceed the recreational screen time guidelines of the } 24 \\
\text { h movement guidelines }\end{array}$ & 27 & $89 \%$ & $\begin{array}{l}7.7 \\
(1.8)\end{array}$ & $8(1.3)$ \\
\hline \multicolumn{5}{|l|}{ Sedentary Behaviour } \\
\hline That sedentary activities are balanced with physical activity & 27 & $85 \%$ & $\begin{array}{l}7.6 \\
(1.2)\end{array}$ & $8(1.0)$ \\
\hline That sedentary activities are available to allow "rest and recharge"/ "wind-down" time & 27 & $81 \%$ & $\begin{array}{l}7.2 \\
(1.5)\end{array}$ & $7(0.8)$ \\
\hline That staff carefully plan the session to consider the needs of the children & 27 & $96 \%$ & $\begin{array}{l}7.8 \\
(1.6)\end{array}$ & $8(1.1)$ \\
\hline $\begin{array}{l}\text { That ongoing staff training and education is provided to ensure a balanced session with a } \\
\text { student centred approach }\end{array}$ & 27 & $93 \%$ & $\begin{array}{l}7.7 \\
(1.3)\end{array}$ & $8(1.1)$ \\
\hline \multicolumn{5}{|l|}{ Other } \\
\hline $\begin{array}{l}\text { That OSHC educators are provided ongoing training and education to develop the Health } \\
\text { and Physical Education curriculum in OSHC }\end{array}$ & 27 & $85 \%$ & $\begin{array}{l}7.2 \\
(1.7)\end{array}$ & $7(1.1)$ \\
\hline $\begin{array}{l}\text { To provide children and families with information of the health benefits of following the } 24 \\
\mathrm{~h} \text { movement guidelines }\end{array}$ & 27 & $89 \%$ & $\begin{array}{l}7.4 \\
(1.7)\end{array}$ & $7(1.1)$ \\
\hline
\end{tabular}

MADM Mean absolute deviation from median, SD Standard deviation \# New Question to Round 3, ${ }^{\text {a }}$ Rated NOT IMPORTANT, SD Standard deviation, MADM Mean absolute deviation from mean

implementation were 1) appropriate staff training, 2) ensuring educator understanding and 3) workplace policy. Online education/training sessions with electronic resources were the preferred methods of resource delivery, with a duration of $60 \mathrm{~min}$.

Following Round 4, the guidelines were refined based on feedback. In particular, to address the concern that it would be impossible for OSHC directors to ensure all children achieved the PA components of the guidelines, the guidelines were reframed so that they were aimed at the OSHC service level rather than the child level. This meant that, instead of the guidelines stating how much PA each child should receive (which is beyond the OSHC director's control, due to child-level factors such

\begin{tabular}{|l|l|l|}
\hline Session & Physical Activity & Recreational Screen Time* \\
\hline Before School Care & $\begin{array}{l}\text { Encourage children to engage in a } \\
\text { variety of physical activities, of } \\
\text { which } \mathbf{1 5} \text { minutes or more is } \\
\text { energetic play. More is better. }\end{array}$ & $\begin{array}{l}\text { No more than } \mathbf{3 0} \text { minutes. } \\
\text { Less is better. }\end{array}$ \\
\hline After School Care & $\begin{array}{l}\text { Encourage children to engage in a } \\
\text { variety of physical activities, of } \\
\text { which } \mathbf{3 0} \text { minutes or more is } \\
\text { energetic play. More is better. }\end{array}$ & $\begin{array}{l}\text { No more than } \mathbf{6 0} \text { minutes. } \\
\text { Less is better. }\end{array}$ \\
\hline Vacation Care & $\begin{array}{l}\text { Encourage children to engage in a } \\
\text { variety of physical activities, of } \\
\text { which } \mathbf{6 0} \text { minutes or more is } \\
\text { energetic play spread throughout } \\
\text { the day. More is better. }\end{array}$ & $\begin{array}{l}\text { No more than } \mathbf{2} \text { hours of } \\
\text { recreational screen time } \\
\text { over the entire day. Less is } \\
\text { better. }\end{array}$ \\
\hline
\end{tabular}

*does not include computer use for homework

Fig. 3 First Iteration of Snapshot Guidelines 
as when their caregiver delivers them/collects them from OSHC), the refined guidelines stated how much PA opportunity the service should provide. In doing this, a ratio of 3:1 was selected, based on evidence from previous research in the sector [30,31]. The final iteration of the OSHC PA and screen time guidelines is shown in Fig. 4.

\section{Discussion}

This study used an international consensus Delphi survey to inform the development of PA and screen time guidelines for Australian OSHC services. This was achieved using key concepts identified and valued by Delphi panel members, combined with the GRADE approach incorporating evidence from recent systematic and scoping reviews $[17,28]$. A range of experts in the field of PA and screen time were involved in the Delphi surveys, with significant input from stakeholder groups such as OSHC educators and families. The Delphi survey identified several key concepts that were applied in the draft guidelines. The main PA concept across all aspects of OSHC was that it should be play-based and fun, with ample opportunity for free active outdoor play. Screen time, if offered at all, should be limited and balanced with PA, whilst quiet sedentary activities should be available to allow children to self-regulate and move freely between active and quiet play. To bring about these changes, OSHC staff should be supported with training to assist them to facilitate PA effectively. Engagement with children and families to help them understand and accept changes (particularly to screen time) will be needed.

Results highlighted that PA in the OSHC setting should be flexible and play-based, rather than PA being structured and run like a physical education class. OSHC occurs during what is normally children's discretionary time i.e. time when children are free to engage in their own pursuits [32]. By providing a guideline that supports children's free play, it enables them to self-regulate, which was an important concept identified in the Delphi process and consistent with the evidence that play-based physical activity is associated with improved social and cognitive development [33-35]. The emphasis on free play in Australian OSHC is consistent with findings from a recent observational study in OSHC in Norway, which reported that over half of children's MVPA was accumulated during outdoor free play [36].

The Delphi survey identified that screen time in OSHC needed limits or rules to govern its use in the setting; with attention to the quantity, quality and the content of screen time identified as important factors. The statement that "Screen time should NOT be a part of OSHC" (i.e. that there should be no screen time at OSHC), did not achieve consensus. While it was strongly supported by some (including OSHC directors whose own services had successfully removed screen time) others (including OSHC directors) strongly wanted screen time in moderation. Some participants stated they were concerned about the amount of screen time children engage in during a school day and once they are home, and that quality OSHC programs shouldn't need to rely on screen time to provide an enjoyable program. If screen time was offered, it could be educational in nature or active gaming e.g. Nintendo Wii or Just Dance programs. Previous literature has highlighted the benefits of active video gaming, demonstrating an improvement in overall PA, mood, self-esteem and other cognitive and academic outcomes (attention, visualspatial skills, academic performance [37]. By contrast,

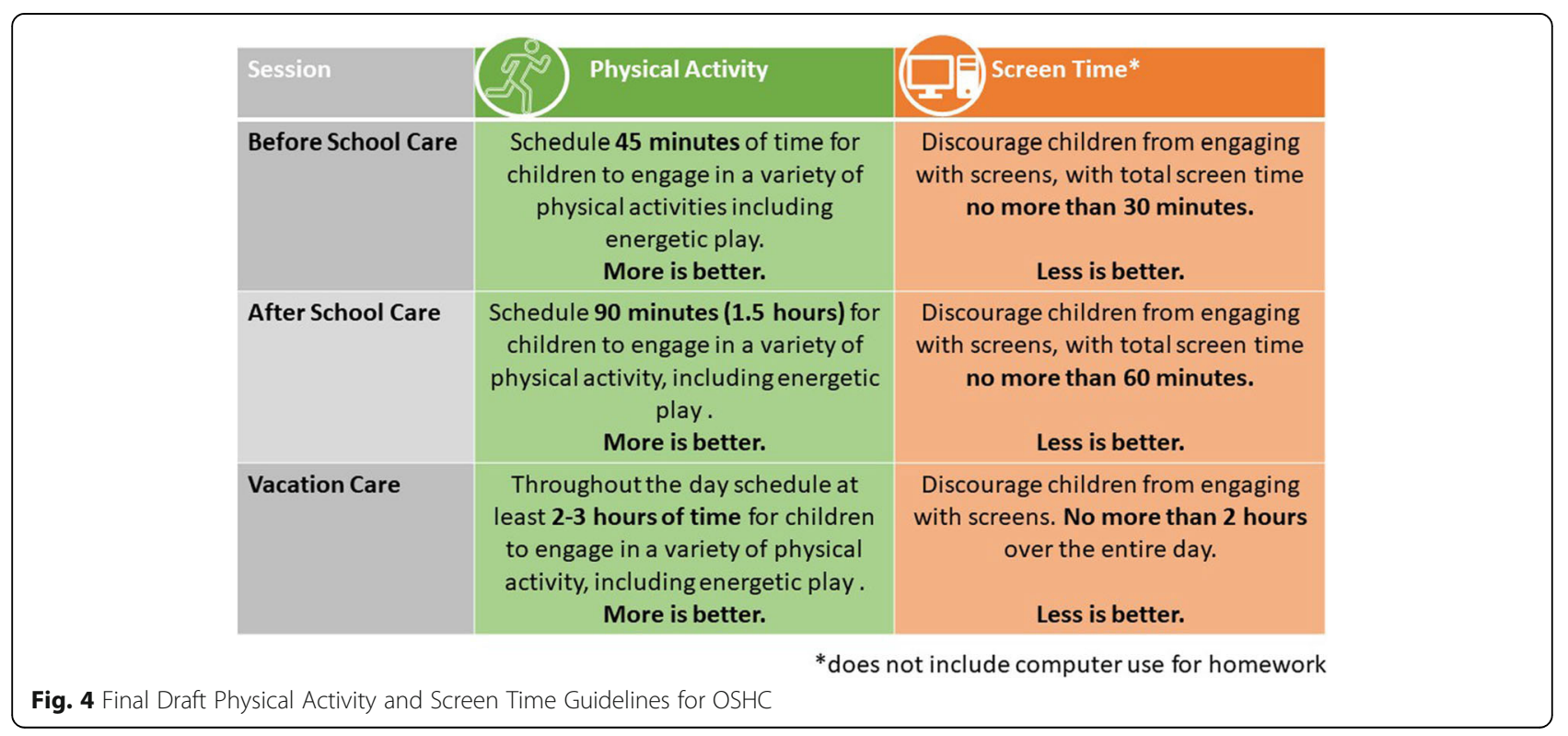


some Delphi participants stated access to screen time was an incentive for children to attend OSHC, as this wasn't available to them at home. It is unclear whether such comments referred to screens not being available by family choice, or due to socioeconomic reasons. Previous Australian research has identified high recreational screen time device ownership amongst children from low SES families [38]. However, it also draws attention to the idea that Australian families using OSHC families are essentially consumers, and OSHC is a product. In Australia, OHSC is most commonly used by working families, whom require care of their children outside of school hours; compared to OSHC in other countries, such as the US, in which OSHC is used for academic enrichment and caters more for low SES children [39]. If children and families using OSHC are consumers, then OSHC services directors may feel pressure to provide programming that children want, so that families will continue to use the service. This may be a barrier to reducing the use of screens in OSHC. Given the contention over the no-screen Delphi item, it makes sense that the statement about providing some screen time in OSHC within limits and rules achieved consensus instead.

Another important point from the screen time comments in the Delphi was that the 24-h movement guidelines need to be considered when programming screen time, particularly for vacation care. Vacation care sessions run during school holidays for an entire day. The Delphi achieved consensus that the 24-h guidelines should not be exceeded during these sessions. This statement is consistent with research that has demonstrated when children achieve the recommended balance of PA, recreational screen time and sleep, as per the 24-h movement guidelines, they have improved cardiorespiratory fitness, health related quality of life and reduced BMI [40]. Rather than banning screen time altogether during this session, it should be balanced with PA and cognitive and social sedentary tasks such as puzzles and board games, which have been demonstrated to have associations with higher academic performance such as writing, numeracy, language, reading and spelling [41].

The Delphi was able to identify important factors related to staff. In particular, the statements that pertained to the importance of staff modelling appropriate screen time behaviours, helping children to move between activities, and having a policy or guidelines to help them plan appropriate PA, screen time and sedentary behaviours in OSHC all reached immediate consensus. This too is consistent with previous research which has found that interventions in a US OSHC setting were more effective when staff display and model behaviours to support healthy eating and PA [42].
Finally, the statement on need for OSHC staff to understand the 24-h movement guidelines and the associated health benefits also reached immediate consensus. While this underscores the importance of knowledge of the Australian children's 24-h movement guidelines amongst OSHC staff, we don't know what the actual level of awareness is at present. Certainly, in other sectors, awareness of physical activity guidelines amongst clinicians and practitioners has been shown to be surprisingly low (for example, a 2017 survey of Australian physiotherapists found that only $10 \%$ could accurately state the physical activity and sedentary behaviour guidelines [43]). Future research examining awareness of the 24-h guidelines amongst OSHC staff, and potentially addressing deficits, is warranted. The many consensus items from Rounds 1-3 of the Delphi informed the draft Australian PA and screen time guidelines for OSHC. They provided important information and ideas that could not have been identified in the scientific literature [22].

\section{Strengths and limitations}

This study had several strengths. The Delphi component of the study was conducted in a rigorous manner, with high participant response rates and representation from a range of national and international experts, stakeholders and end-users. Four rounds of the Delphi were conducted over 7 months with an average response rate of $67 \%$. This result is consistent with a recent systematic review from Gargon et al. [44] which found Delphi response rates varied from 45 to $100 \%$. In addition to this, this Delphi survey was novel in that a large proportion of the participants were end-users (OSHC educators and parents combined represented $51 \%$ of the survey participants). This is a change to traditional Delphi surveys, which typically are for clinical purposes e.g. in palliative care Delphi techniques are used to develop clinical guidelines for treatment recommendations and assessment tools when it is inappropriate to use other typical research methods (i.e. RCTs, observational studies) [24] . This is a novel approach to a Delphi technique and allows for crucial end-user engagement, and is becoming more apparent in the literature $[45,46]$. This is consistent with contemporary population health research approaches, which recognise that best practice is to involve patients or the public with research that not only helps to identify appropriate priorities, but is more relevant to user needs [47]. The Delphi also identified barriers and enablers to implementing such a guideline into this setting. These were factors such as educator beliefs and workplace culture. This is an important step for future implementation research, as it has provided some initial data that organisational issues are likely to be a barriers to implementation [48]. Practical information was also 
obtained about the best way to engage with OSHC educators through training workshops, approximately 60 min in duration with ongoing access to resources and support. This is important, as the turn-over of staff in the OSHC setting is high, and professional development opportunities limited. Thus, any resources that are developed need to be easily accessible, time-efficient and easily understood [49].

The second component of this study was the development of draft Australian PA and screen time guidelines. This followed the GRADE process, which is considered the gold standard in guideline development [23] and allowed for not only the use of evidence from systematic reviews, but also incorporated the consensus items from participants of the Delphi. This approach allowed for further stakeholder input into the guidelines and contributes to the strength of the draft guidelines. This was reflected in the results from Round 4 when the wording and recommendations of the draft Australian PA and screen time guidelines were well received by participants, with few concerns over the time durations recommended and many positive comments on the appropriateness of the wording.

Some limitations to this Delphi survey were that despite the rigour in method used and the best efforts of the research team to engage participants (using an online forum, with several reminder emails and short survey duration), not all responses were complete, meaning data were sometimes missing from some questions. By design, the Delphi panellists were invited to ensure broad representation of all Australian states and stakeholders, with a view to generating results that are generalisable to the national OSHC context. It is possible that results don't truly represent specialised OSHC settings, for example, OSHC services in remote areas, and OSHC services serving specialised child populations such as single-sex schools, children with disabilities, or services with high numbers of children from different cultural backgrounds.

\section{Implications for future research}

The findings of this study show draft Australian PA and screen time guidelines developed for use in OSHC are welcomed by the sector and the setting has a role in helping children to achieve the 24-h movement guidelines. The use of these guidelines may provide a benchmark for services to aim for during OSHC sessions and a way in which they can continually improve practice through self-assessment against the guidelines. The draft guidelines also support the Australian National Quality Framework standards that Australian OSHC services need to meet - particularly standard 2.1 "That children's health and physical activity are supported and promoted" [50]. Future research should build on this initial work, by further refining and assessing the guidelines through end-user validation, followed by widespread implementation and dissemination assessment of these guidelines into daily OSHC practice. Key barriers and enablers were also identified from this study relating to workplace culture and children's expectations in OSHC, which will be important to consider in future research.

\section{Conclusion}

Extensive engagement, representing a variety of stakeholders, including strong representation from end-users, resulted in a series of consensus statements regarding $\mathrm{PA}$ and screen time in OSHC setting, which informed the development of draft Guidelines for PA and screen time guidelines in Australian OSHC. These guidelines will provide a benchmark for OSHC services to provide quality PA and screen time programming. Training and support to assist OSHC staff to facilitate quality PA is needed and should be designed to acknowledge the constraints of OSHC workforce (characterised by high levels of casualisation, and staff turn-over). In addition, involvement of children and parents will be important to aid the acceptability of that changes in PA and screen time practices in OSHC services.

\section{Supplementary Information}

The online version contains supplementary material available at https://doi. org/10.1186/s12966-020-01061-z.

\section{Additional file 1. \\ Additional file 2 \\ Additional file 3}

\section{Abbreviations}

MVPA: Moderate - to- vigorous physical activity; PA: Physical activity; OSHC: Outside school hours childcare

\section{Acknowledgements}

We would like to thank the Guideline Development Panel, which consisted of: Professor Michael Beets - University of South Carolina. Associate Professor Lucy Lewis - Flinders University. Associate Professor Carol Maher - University of South Australia.

Professor Tony Okely - University of Wollongong.

Ms. Mandy Richardson - Industry representative NOSHA - South Australian Branch.

Professor Ric Rosenkranz - Kansas State University.

Ms. Rosa Virgara - University of South Australia.

Associate Professor Luke Wolfenden - University of Newcastle and the many Delphi participants who chose not to be named.

\section{Authors' contributions}

$\mathrm{RV}, \mathrm{CM}, \mathrm{LL}, \mathrm{AP}$ and $\mathrm{MR}$ conceptualised the Delphi survey and contributed to the writing of the manuscript. RV administered the Delphi survey via online survey platform and was responsible for data analysis. RV, CM, LL, AP and MR read and approved the final manuscript for publication.

Funding

This research did not receive any specific grant from funding agencies in the public, commercial, or not-for-profit sectors. Rosa Virgara is a PhD candidate at the University of South Australia and is supported by a RTPd Stipend. In 
addition, she is supported by a Top Up Scholarship from Health Development Adelaide, University of Adelaide.

Carol Maher is supported by an NHMRC Career Development Fellowship (APP1125913). These funding bodies did not have any role in the study's conception, design, analysis, interpretation of data or writing of this manuscript.

\section{Availability of data and materials}

The datasets used and/or analysed during the current study are available from the corresponding author on reasonable request.

\section{Ethics approval and consent to participate}

Ethics approval was sought and gained from the University of South Australia Human Ethics Research Committee (protocol no. 201786).

Participants provided individual informed consent by completing the survey, as described in the methods of the study.

\section{Consent for publication}

We would like to thank all the Delphi participants, of whom the following gave consent to be named:

Dr. Lauren Arundell - Research Fellow Deakin University, Mr. Rick Baldock Professional Learning Coordinator - ACHPER (SA), Associate Professor Lauren Ball - Research Fellow Griffith University, Ms. Kylie-Anne Brannelly - President NOSHA QLD Branch/QCAN,

Mr. Andrew Bradley - Exercise Physiologist Adelaide Paediatrics, Dr. Aaron Beighle - Professor, Department of Kinesiology and Health Promotion University of Kentucky, Mr. Perry Campbell - Senior Manager ACECQA, Ms. Kerry Carradus - OSHC Co-ordinator, Dr. Jean-Philippe Chaput - Research Scientist CHEO Healthy Active Living and Obesity Research (HALO) Canada, Ms. Carolyn Cheah - Parent, Dr. Anthony Chitti (MBBS) - Pediatrician Calvary North Adelaide Hospital, Associate Professor Hayley Christian - Senior Research Fellow University of Western Australia/Telethon Kids Institute, Dr. Casey Gray -Clinical Research officer CHEO Healthy Active Living and Obesity Research (HALO) Canada, Ms. Rebekah Harrison - Physical Activity Officer Australian Federal Government,

Dr. Peter T Katzmarzyk - Professor Physical Activity and Obesity Epidemiology Pennington Biomedical Research Center - Louisiana State University, Ms. Elaine Marshall - Physical Activity Officer Australian Federal Government, Ms. Shannon Parrish-Hill - OSHC Co-ordinator, Dr. Rebecca Stanley - Research Fellow University of Wollongong, Dr. Grant Tomkinson Professor Education, Health and Behaviour University of North Dakota, Mr. Timothy Ward - Parent, Mr. Mark Williams - Manager of the Premier's Challenges Department for Education South Australia.

\section{Competing interests}

The authors declare that they have no competing interests.

\section{Author details}

${ }^{1}$ Allied Health and Human Performance, University of South Australia, c/o GPO Box 2471, SA 5001 Adelaide, Australia. ${ }^{2}$ Caring Futures Institute, College of Nursing and Health Sciences, Flinders University, Adelaide, Australia.

${ }^{3}$ OSHC SA Chairperson, NOSHA SA Branch, Adelaide, Australia.

Received: 29 September 2020 Accepted: 20 November 2020

Published online: 06 January 2021

\section{References}

1. Okely AD, Ghersi D, Hesketh KD, Santos R, Loughran SP, Cliff DP, et al. A collaborative approach to adopting/adapting guidelines-the Australian 24hour movement guidelines for the early years (birth to 5 years): an integration of physical activity, sedentary behavior, and sleep. BMC Public Health. 2017;17(5):869.

2. Tremblay MS, Carson V, Chaput J-P, Connor Gorber S, Dinh T, Duggan M, et al. Canadian 24-hour movement guidelines for children and youth: an integration of physical activity, sedentary behaviour, and sleep. Appl Physiol Nutr Metab. 2016:41(6):S311-S27.

3. Jurakić D, Pedišić Ž. Croatian 24-hour guidelines for physical activity, sedentary behaviour, and sleep: A proposal based on a systematic review of literature. Medicus. 2019;28(2 Tjelesna aktivnost):143.

4. New Zealand Ministry of Health. Sit Less, Move More, Sleep Well: Physical Activity Guidelines for Children and Young People. 2017.
5. Reiner M, Niermann C, Jekauc D, Woll A. Long-term health benefits of physical activity-a systematic review of longitudinal studies. BMC Public Health. 2013;13(1):1-9.

6. Ian J, Roberts Karen C, Thompson W. Adherence to the 24-hour movement guidelines among 10-to 17-year-old Canadians. Health Promot Chronic Dis Prev Can. 2017:37(11):369.

7. Aubert S, Barnes JD, Aguilar-Farias N, Cardon G, Chang C-K, Nyström CD, et al. Report card grades on the physical activity of children and youth comparing 30 very high human development index countries. J Phys Act Health. 2018;15(S2):S298-314 PubMed PMID: 30475144.

8. Aubert S, Barnes JD, Abdeta C, Abi Nader P, Adeniyi AF, Aguilar-Farias N et al. Global matrix 3.0 physical activity report card grades for children and youth: results and analysis from 49 countries. J Phys Act Health. 2018;15(s2): S251-S73

9. Olds T, Wake M, Patton G, Ridley K, Waters E, Williams J, et al. How do school-day activity patterns differ with age and gender across adolescence? J Adolesc Health. 2009:44(1):64-72 PubMed PMID: 19101460. Epub 2008/12/ 23. eng.

10. Arundell L, Hinkley T, Veitch J, Salmon J. Contribution of the After-School Period to Children's Daily Participation in Physical Activity and Sedentary Behaviours. PLoS One. 2015;10(10):11 PubMed PMID: WOS: 000363920800002 . English.

11. Beets M, Shah R, Weaver RG, Huberty J, Beighle A, Moore J. Physical activity in after-school programs: comparison with physical activity policies. J Phys Act Health. 2015;12(1):1-7.

12. Australian Bureau of Statistics. Childhood Education and Care. In Australian Bureau of Statistics. Canberra; 2017. Accessed online at http://www.abs.gov. au/AUSSTATS/abs@.nsf/DetailsPage/4402.0June\%202017?OpenDocument.

13. The Norwegian Directorate for Education and Training. The Education Mirror. Facts and Analyses of Kindergartens, Primary and Secondary Education in Norway. Oslo: The Norwegian Directorate of Education and Training; 2016.

14. Cradock AL, Barrett JL, Giles CM, Lee RM, Kenney EL, DeBlois ME, et al. Promoting physical activity with the out of school nutrition and physical activity (OSNAP) initiative a cluster-randomized controlled trial. JAMA Pediatr. 2016:170(2):155-62 PubMed PMID: 608135000

15. Dzewaltowski DA, Rosenkranz RR, Geller KS, Coleman KJ, Welk GJ, Hastmann TJ, et al. HOP'N after-school project: an obesity prevention randomized controlled trial. Int J Behav Nutr Phys Act. 2010;7(1):90

16. Beets MW, Weaver RG, Turner-McGrievy G, Huberty J, Ward DS, Pate RR, et al. Making policy practice in afterschool programs: a randomized controlled trial on physical activity changes. Am J Prev Med. 2015;48(6):694706.

17. Virgara R, Lewis LK, Phillips A, Richardson M, Maher CA. Guidelines for physical activity and screen-time in the outside school hours childcare setting: a scoping review; 2020

18. Guyatt GH, Oxman AD, Kunz R, Vist GE, Falck-Ytter Y, Schünemann HJ. What is "quality of evidence" and why is it important to clinicians? BMJ. 2008; 336(7651):995-8.

19. Schünemann HJ, Wiercioch W, Etxeandia I, Falavigna M, Santesso N, Mustafa $\mathrm{R}$, et al. Guidelines 2.0: systematic development of a comprehensive checklist for a successful guideline enterprise. Cmaj. 2014;186(3):E123-E42.

20. Research. UIfHP. Aikuisten liikkumisen suositus [Movement Recommendations for Adults]. 2018.

21. Draper CE, Tomaz SA, Biersteker L, Cook CJ, Couper J, Md M, et al. The South African 24-Hour Movement Guidelines for Birth to 5 Years: An Integration of Physical Activity, Sitting Behavior, Screen Time, and Sleep. J Phys Act Health. 2020;17(1):109 English.

22. Guyatt GH, Oxman AD, Kunz R, Atkins D, Brozek J, Vist G, et al. GRADE guidelines: 2. Framing the question and deciding on important outcomes. J Clin Epidemiol. 2011;64(4):395-400

23. Guyatt GH, Oxman AD, Akl EA, Kunz R, Vist G, Brozek J, et al. GRADE guidelines: 1. Introduction—GRADE evidence profiles and summary of findings tables. J Clin Epidemiol. 2011:64(4):383-94.

24. Jünger S, Payne SA, Brine J, Radbruch L, Brearley SG. Guidance on conducting and REporting DElphi studies (CREDES) in palliative care: recommendations based on a methodological systematic review. Palliat Med. 2017:31(8):684-706 PubMed PMID: 28190381.

25. Hsu C-C, Sandford BA. The Delphi technique: making sense of consensus. Pract Assess Res Eval. 2007:12(1):10

26. GmbH L. LimeSurvey: an open survey tool; 2019 
27. Sinha IP, Smyth RL, Williamson PR. Using the Delphi technique to determine which outcomes to measure in clinical trials: recommendations for the future based on a systematic review of existing studies. PLoS Med. 2011; 8(1):e1000393.

28. Virgara R, Maher C, Lewis LK, Phillips A, Wolfenden L, Okely A, et al. Interventions in outside-school hours childcare settings for promoting physical activity amongst schoolchildren aged 4 to 12 years. Cochrane Database Syst Rev. 2019;7(Art. No. CD013380). https://doi.org/10.1002/ 14651858.CD013380

29. Elamir E. Mean absolute deviation about median as a tool of explanatory data analysis. Proceedings of the World Congress on Engineering; 2012.

30. Brazendale K, Beets MW, Weaver RG, Huberty J, Beighle AE, Pate RR. Wasting our time? Allocated versus accumulated physical activity in afterschool programs. J Phys Act Health. 2015;12(8):1061-5.

31. Rosenkranz RR, Welk GJ, Dzewaltowski DA. Environmental correlates of objectively measured physical activity and sedentary behavior in afterschool recreation sessions. J Phys Act Health. 2011:8(s2):S214-S21.

32. Beighle A, Morgan CF, Le Masurier G, Pangrazi RP. Children's physical activity during recess and outside of school. J Sch Health. 2006;76(10):516-20.

33. Whitebread D, Neale D, Jensen H, Liu C, Solis SL, Hopkins E, et al. The role of play in children's development: a review of the evidence: LEGO Fonden; 2017.

34. Becker DR, McClelland MM, Loprinzi P, Trost SG. Physical activity, selfregulation, and early academic achievement in preschool children. Early Educ Dev. 2014;25(1):56-70.

35. Whitebread D, Coltman P, Jameson H, Lander R. Play, cognition and selfregulation: what exactly are children learning when they learn through play? Educ Child Psychol. 2009;26(2):40.

36. Riiser K, Haugen AL, Lund S, Løndal K. Physical activity in young schoolchildren in after school programs. J Sch Health. 2019;89(9):752-8.

37. Staiano AE, Calvert SL. Exergames for physical education courses: physical, social, and cognitive benefits. Child Dev Perspect. 2011;5(2):93-8.

38. Dumuid D, Olds TS, Lewis LK, Maher C. Does home equipment contribute to socioeconomic gradients in Australian children's physical activity, sedentary time and screen time? BMC Public Health. 2016;16(1):736

39. Simoncini K, Lasen M. Support for quality delivery of outside school hours care: a case study. Australas J Early Childhood. 2012;37(2):82-94.

40. Rollo S, Antsygina O, Tremblay MS. The whole day matters: Understanding 24-hour movement guideline adherence and relationships with health indicators across the lifespan. J Sport Health Sci. 2020. https://doi.org/10 1016/j.jshs.2020.07.004

41. Maher C, Lewis L, Katzmarzyk PT, Dumuid D, Cassidy L, Olds T. The associations between physical activity, sedentary behaviour and academic performance. J Sci Med Sport. 2016;19(12):1004-9.

42. Weaver RG, Beets MW, Beighle A, Webster C, Huberty J, Moore JB. Strategies to increase after-school program staff skills to promote healthy eating and physical activity. Health Promot Pract. 2016;17(1):88-97.

43. Freene N, Cools S, Bissett B. Are we missing opportunities? Physiotherapy and physical activity promotion: a cross-sectional survey. BMC Sports Sci Med Rehabil. 2017:9(1):1-8

44. Gargon E, Crew R, Burnside G, Williamson PR. Higher number of items associated with significantly lower response rates in COS Delphi surveys. J Clin Epidemiol. 2019;108:110-20.

45. McMaster CM, Wade T, Franklin J, Hart S. Development of consensus-based guidelines for outpatient dietetic treatment of eating disorders: a Delphi study. Int J Eat Disord. 2020:53(9):1480-95.

46. Baldwin CE, Phillips AC, Edney SM, Lewis LK. Recommendations for older adults' physical activity and sedentary behaviour during hospitalisation for an acute medical illness: an international Delphi study. Int J Behav Nutr Phys Act. 2020;17(1):1-17.

47. Gray-Burrows KA, Willis TA, Foy R, Rathfelder M, Bland P, Chin A, et al. Role of patient and public involvement in implementation research: a consensus study. BMJ Qual Saf. 2018;27(10):858-64

48. Nathan N, Elton B, Babic M, McCarthy N, Sutherland R, Presseau J, et al. Barriers and facilitators to the implementation of physical activity policies in schools: a systematic review. Prev Med. 2018;107:45-53.

49. Hurd N, Deutsch N. SEL-focused after-school programs. Futur Child. 2017; 27(1):95-115.

50. Australian Children's Education \& Care Quality Authority. National Quality Framework - Quality Area 2 - Children's health and Safety 2018 [Available from: https://www.acecqa.gov.au/nqf/national-quality-standard/qualityarea-2-childrens-health-and-safety.

\section{Publisher's Note}

Springer Nature remains neutral with regard to jurisdictional claims in published maps and institutional affiliations.

\section{Ready to submit your research? Choose BMC and benefit from:}

- fast, convenient online submission

- thorough peer review by experienced researchers in your field

- rapid publication on acceptance

- support for research data, including large and complex data types

- gold Open Access which fosters wider collaboration and increased citations

- maximum visibility for your research: over $100 \mathrm{M}$ website views per year

At $\mathrm{BMC}$, research is always in progress.

Learn more biomedcentral.com/submissions 